\title{
Climate Change: Evaluating Your Local and Regional Water Resources
}

\section{The Basin Characterization Model}

Ongoing changes in climate, particularly rises in air temperature, are influencing water resources throughout the world, with shifts in the timing of precipitation, reductions in snowpack (fig. 1), and earlier springtime snowmelt among the most important challenges to water availability (fig. 2). These changes are affecting landscapes, vegetation and animal species, and agriculture, with longer dry seasons, which also create more demand on water resources, more frequent extreme storms, fewer chilling hours, and higher snowlines.

To plan for future water- and land-resource demands, resource managers have generally relied on data from globalclimate model projections of precipitation and air temperature trends that lack the detail needed for precision planning at regional and local scales. Recently, the U.S. Geological Survey (USGS) has developed modeling tools that integrate climate data with rigorously developed regional and local environmental data to understand the hydrologic response to climate change and the effects on regional and local watersheds and landscapes.
New water-balance modeling tools can provide the types of information managers require to develop climate-change coping strategies:

Watershed recharge and runoff quantification-to assess water availability, seasonality, and extremes at the land surface. Climatic water deficit estimation - to assess irrigation demand or landscape stress (climatic water deficit is the amount of water plants would use if it were available).

Spatial distribution of hydrologic processes in watershedsfor resource planning and infrastructure development.

To develop management strategies for coping with climate change, land and resource managers need hydrologic derivatives of climate, such as recharge and runoff quantities, to assess water availability or climatic water-deficit estimates to assess projected changes in irrigation demand or landscape stress. Regional water-balance modeling can be used effectively to estimate the spatial distribution of these hydrologic variables and can differentiate between recharge and runoff to provide valuable information for resource planning and infrastructure development.

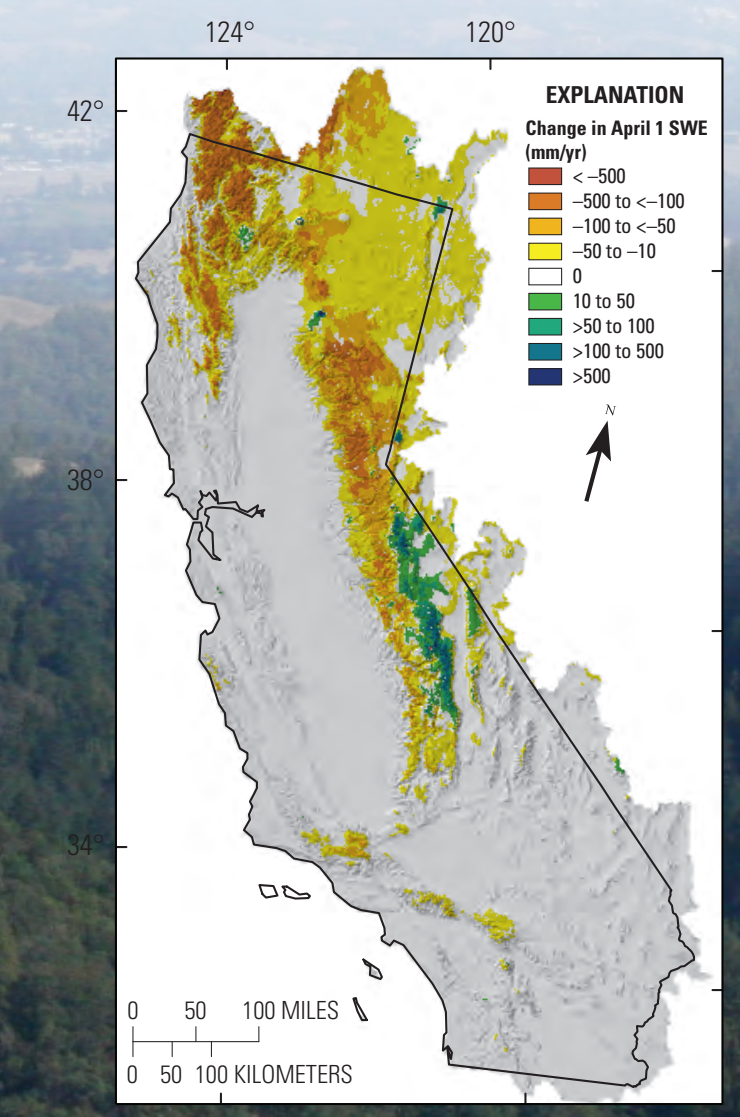

Figure 1. Change in snow water equivalent (SWE) between 1951-1980 and 1981-2010 in California. These decreases in snowpack reflect world-wide trends in all but the highest elevations over the last half-century.

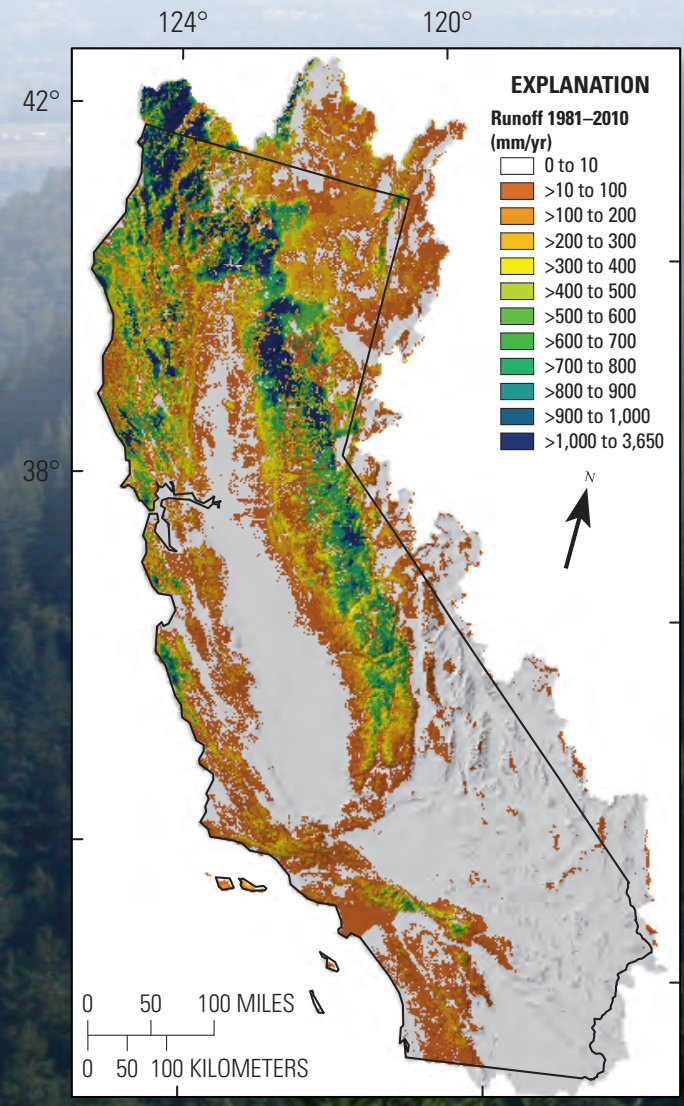

Figure 2. Runoff in California, 1981-2010, estimated by using the Basin Characterization Model, a regional water-balance model used throughout the Western U.S. and internationally. 
The Basin Characterization Model (BCM) is a mathematical computer model that calculates the hydrologic inputs and outputs of a specific landscape area (fig. 3) and is generally run at a monthly timestep for large regions (fig. 1), although daily models have been developed for small watersheds. Scientists divide the landscape into grid cells, each of which uses specific climate data inputs, such as precipitation and air temperature, to solve the water balance for each cell. Model calculations include potential evapotranspiration, calculated from solar radiation with topographic shading and cloudiness; snow, as it accumulates and melts; and excess water moving through the soil profile, which is used to calculate actual evapotranspiration and climatic water deficit - the difference between potential and actual evapotranspiration. Depending on soil properties and the permeability of underlying bedrock, surface water can be classified for each cell as either recharge or runoff. Post-processing calculations are made to estimate baseflow, streamflow, and potential recharge to the groundwater system for watersheds (fig. 4). The model output can define the water balance for any size polygon representing regions or watersheds, or can define the distribution of the various water-balance variables across the landscape.

\section{Processes represented in the BCM}

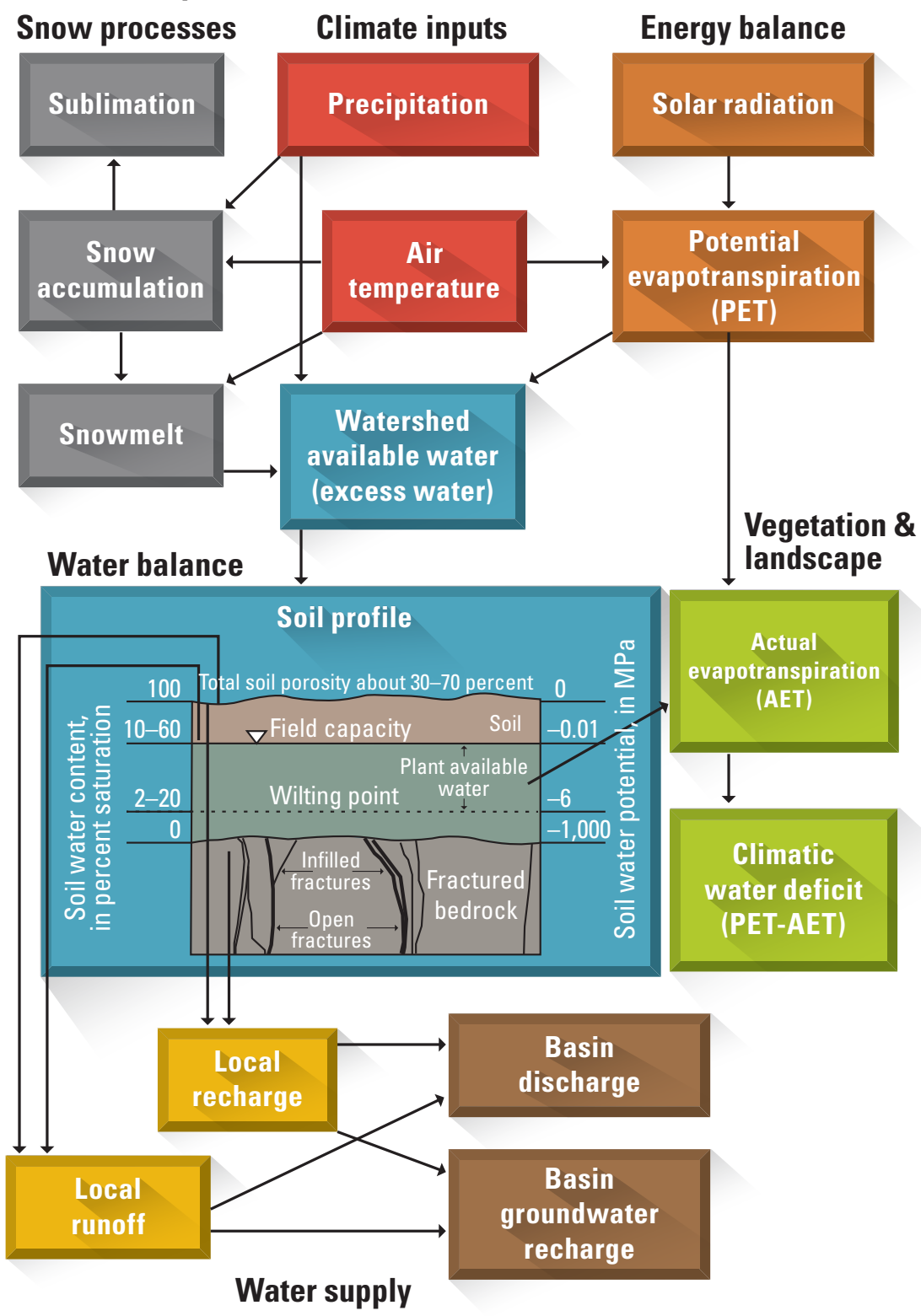

Figure 3. The Basin Characterization Model relies on climate input and the rigorous development of potential evapotranspiration to move water through the soil profile and into underlying bedrock to become recharge or runoff. [MPa, megapascal] 


\section{Global-Climate Models and Downscaling}

Downscaling to 270-meters captures data with enough detail to reflect the deterministic factors influencing the water balance (energy loads, topographic shading) and enables the use of landscape-level mapping of soil properties, vegetation distributions, and land use to improve the characterization of watershed and landscape processes and climate (fig. 4).
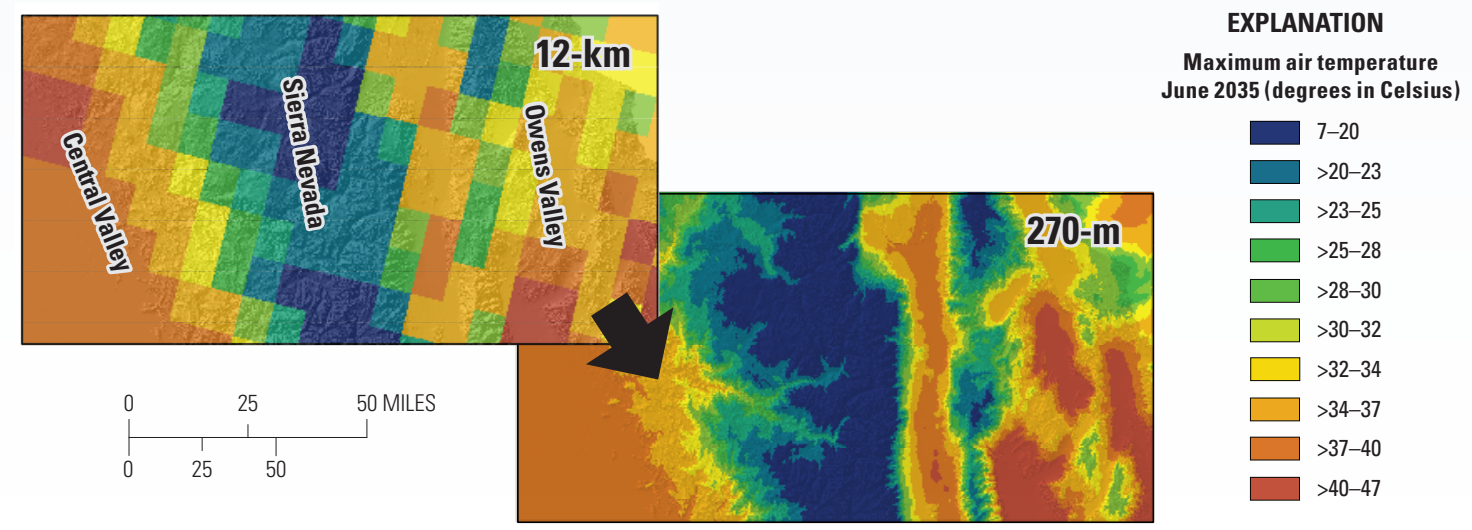

Figure 4. Global Climate Models that project changes in precipitation and air temperature for the 21 st century are downscaled to fine spatial scales for application to process-based hydrologic models.

\section{Calibration and Uncertainty: What Does This Mean to Your Management Issue?}

In general, models are calibrated to optimize model output accuracy by minimizing the differences between simulated model outputs and observations. BCM calibrations have been done for basins throughout the western U.S. The BCM calculates unimpaired streamflow and compares it to streamflow in unregulated, upstream tributaries, such as Upper Dry Creek in the Russian River Basin (fig. 5A). Streamflow diversions and estimates of agricultural demand can be included in the calibration for comparison with impaired mainstem streamflow, such as those measured downstream at the Guerneville gage. A final mainstem calibration at a daily timestep is shown for the Russian River at Hopland, California (fig. 5B), which provides confidence in the model extrapolating streamflow into the future.

$\boldsymbol{A}$
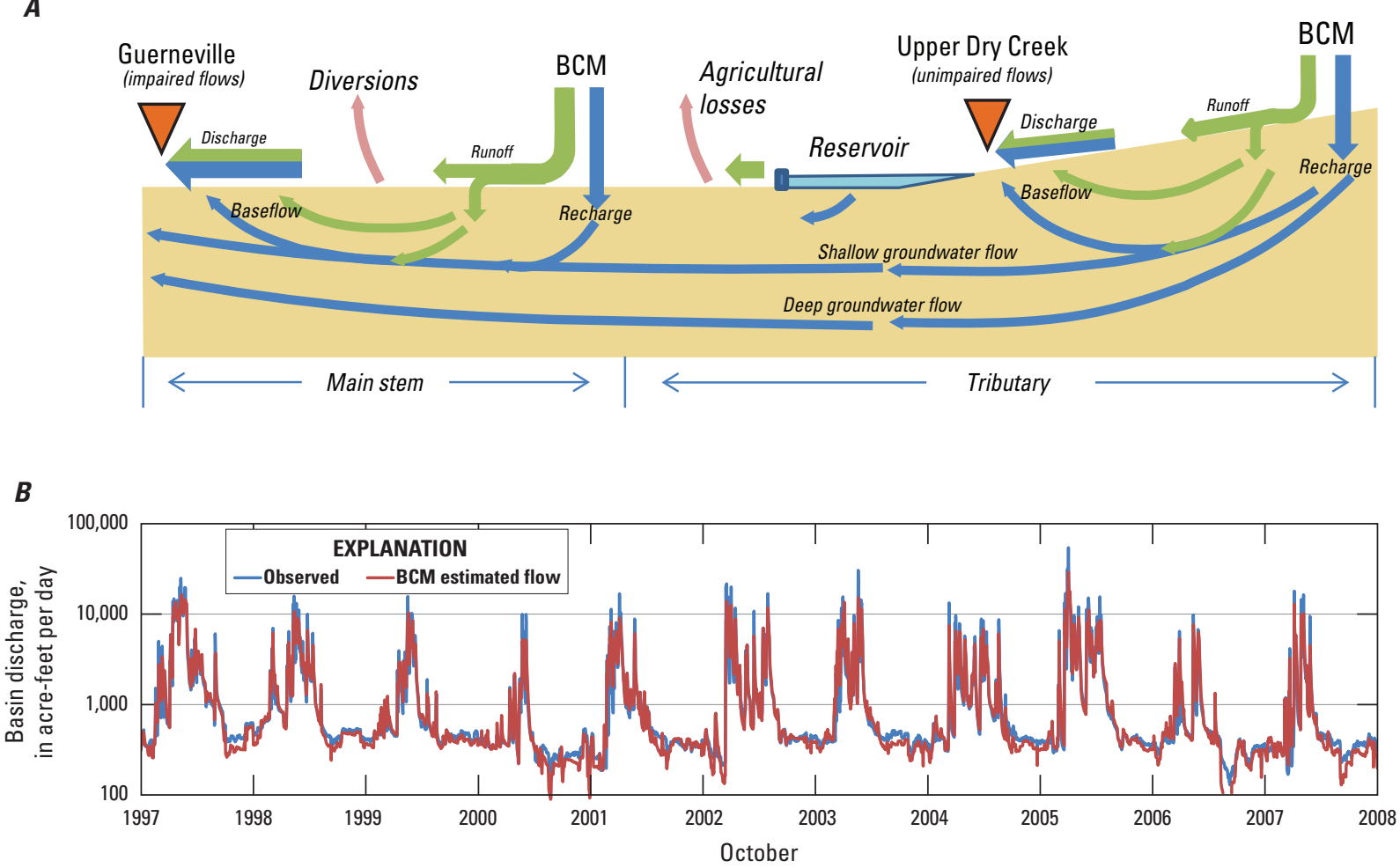

Figure 5. Basin Characterization Model (BCM) model calibration is based on streamflow measurements, shown as an example using $A$, a schematic of the flow

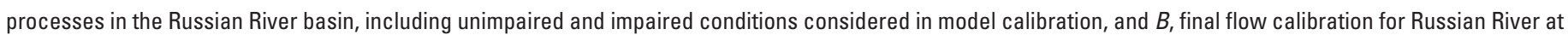
Hopland, California. 


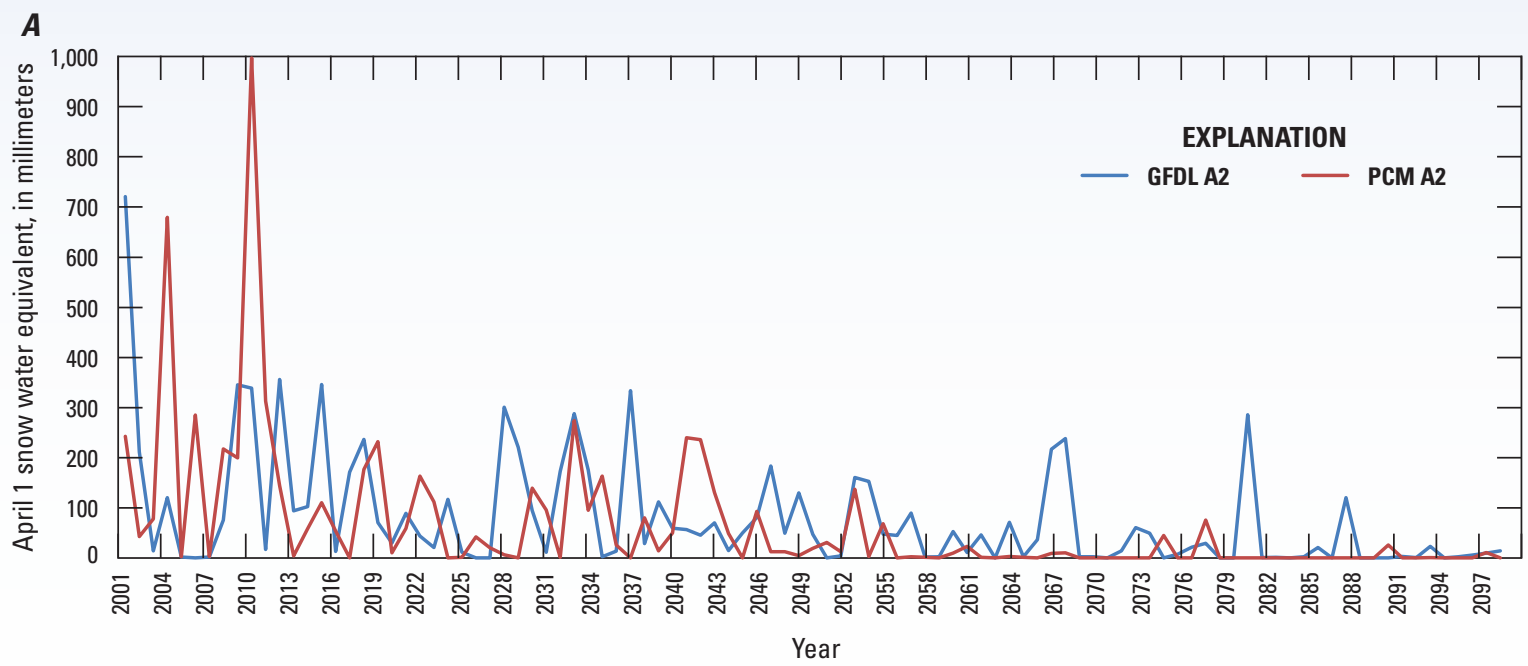

Figure 6. Change in April 1st snow water equivalent projected to the end of the 21st century is shown $A$, for the Indian Creek basin and $B$, change in recharge is shown for the entire Klamath River Basin.

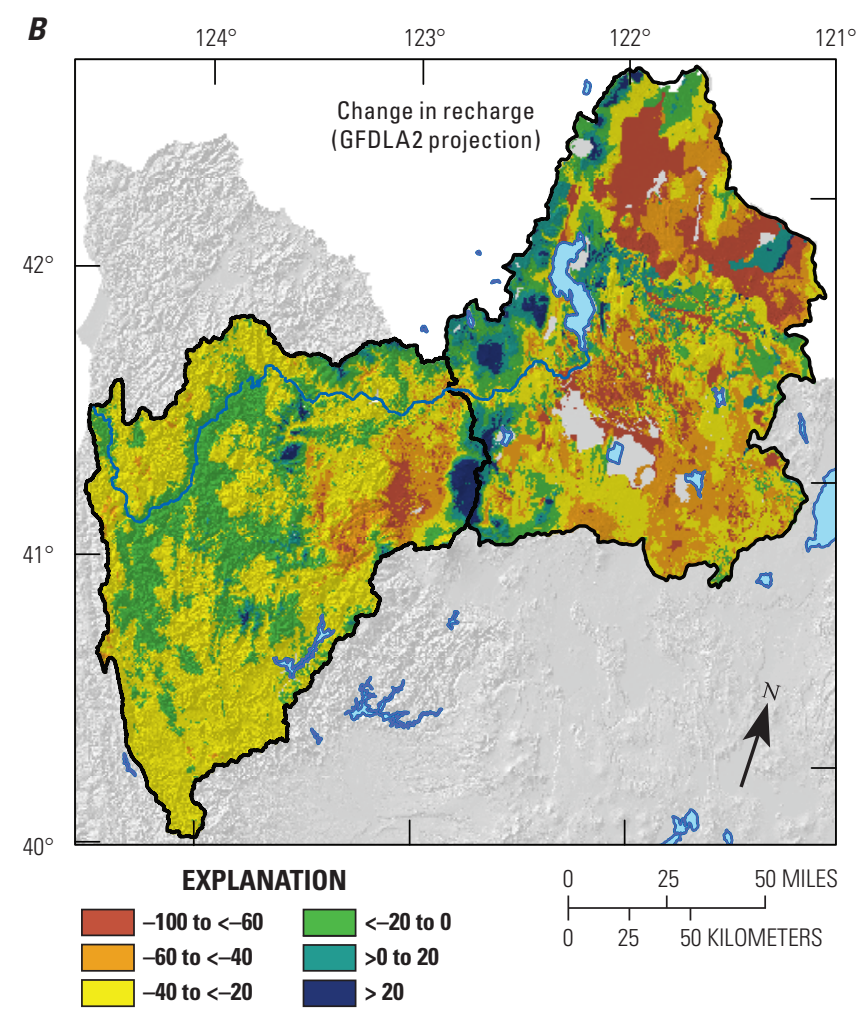

Change, in percent

1971 to $2000 \longrightarrow 2071$ to 2100

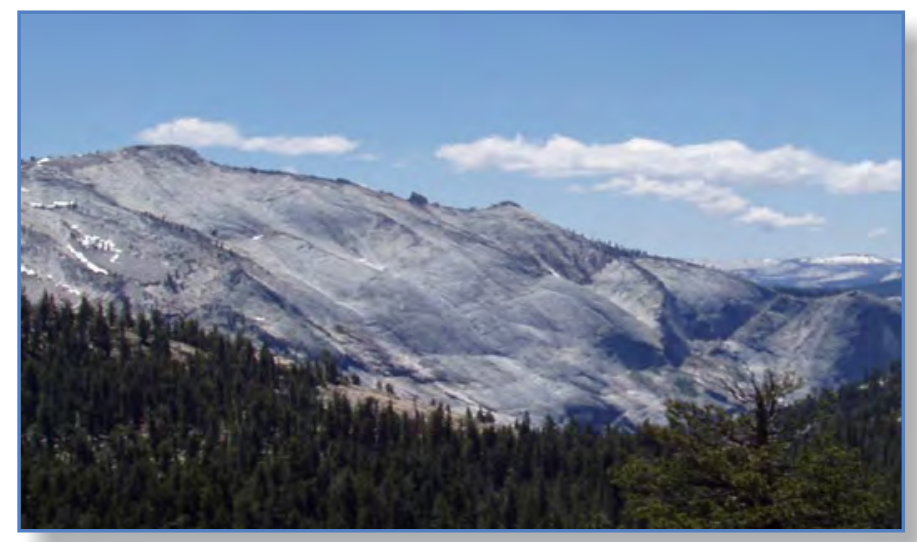

Photo taken by L.E. Flint.

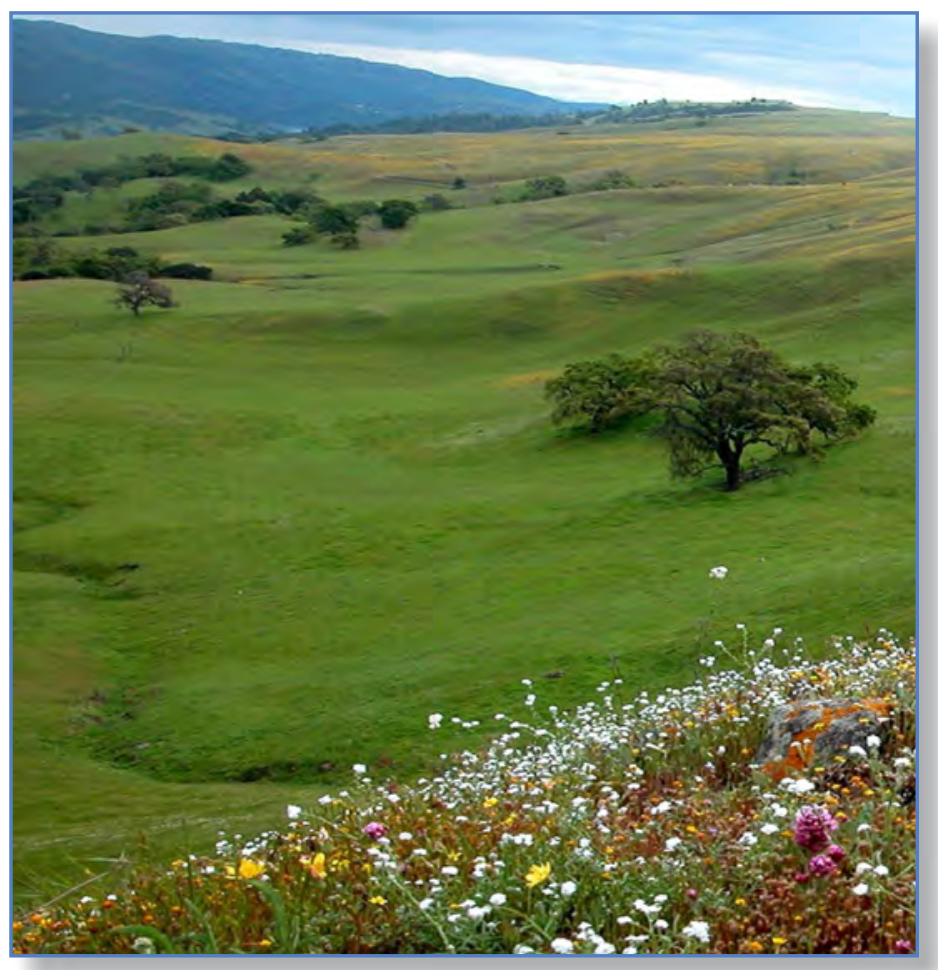

Photo taken by S.B. Weiss.

\section{Climate Change Affects Water Availability in Several Ways}

\section{Timing and Amount}

The timing of springtime snowmelt is controlled by air temperature and has been earlier in recent years (fig. 6A). Regardless of the amount of precipitation, less is likely to fall as snow, and snowpack will not maintain the water supply as long into the dry season as at present (fig. 6B).

\section{Extremes}

Atmospheric rivers bringing large winter storms, along with extended droughts, create conditions leading to flooding, to declines in water quality, to agricultural effects, and to threats to fisheries. 


\section{Climate Change and Infrastructure Needs}

The dominant natural hydrologic process that brings water into a watershed influences the kind of infrastructure that has been developed to store and move water to users. With climate change, these natural hydrologic processes can shift, possibly causing a need for new infrastructure or water-supply management changes. These shifts reflect changes in the seasonal timing of precipitation and snowmelt, which, when combined with soil thickness, influence how much water recharges basin groundwater rather than runs off. Loss of snow cover, along with the presence of deep soils, can increase recharge during climate-related compressed wet seasons and the longer dry seasons. In contrast, where there are shallow soils, higher peak flows can increase runoff. For example, the Russian, Tuolumne, Merced, and American River Basins all rely heavily on reservoir storage to maintain the water supply and to sustain it through the dry season. In the American River Basin, there is a projected increase in recharge relative to runoff (fig. 7). The Russian River, Tuolumne, and Merced could be losing recharge. These changes can affect downstream reservoir operations to the extent that efforts to implement groundwater-storage management changes are warranted.

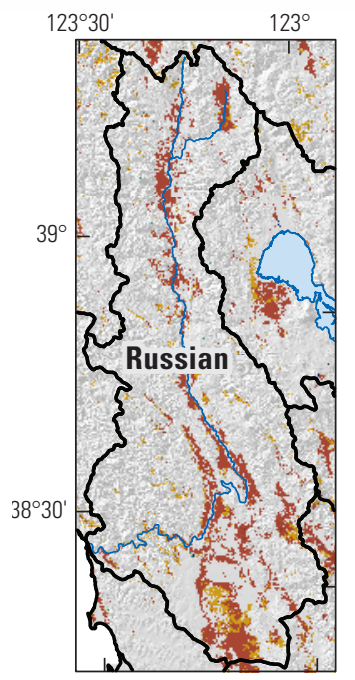

\section{EXPLANATION}

Change in ratio of recharge to runoff (1981-2010) to (2071-2100)

\begin{tabular}{|c|c|}
\hline$<-2$ & Recharge/runoff decreases \\
\hline-2 to -1 & \\
\hline$>-1$ to 1 & \\
\hline$>1$ to 2 & \\
\hline$>2$ & Recharge/runoff increases \\
\hline
\end{tabular}

Figure 7. Change in ratio of recharge to runoff for the GFDL A2 projection. Cool colors indicate an increase in recharge relative to runoff; warm colors indicate a decrease in recharge relative to runoff.

\section{Effects to Landscapes, Vegetation, and Agriculture}

\section{Climatic Water Deficit (CWD)}

The CWD is the annual evaporative demand that exceeds available water. It is calculated as potential evapotranspiration minus actual evapotranspiration and integrates climate, energy loading, drainage, and changes in soil moisture in a single variable (fig. $8 A$ ). It is strongly correlated with the distribution of vegetation in a landscape. Because the CWD accumulates the deficit over the season, it is an indicator of the irrigation demand required to make up the seasonal deficit. Interestingly, because the CWD is limited by the capacity of soils to hold extra precipitation that would become runoff or recharge during the wet season, by the end of the summer, it increases with all climate change scenarios, even when wetter years are projected (fig. $8 B$ ).

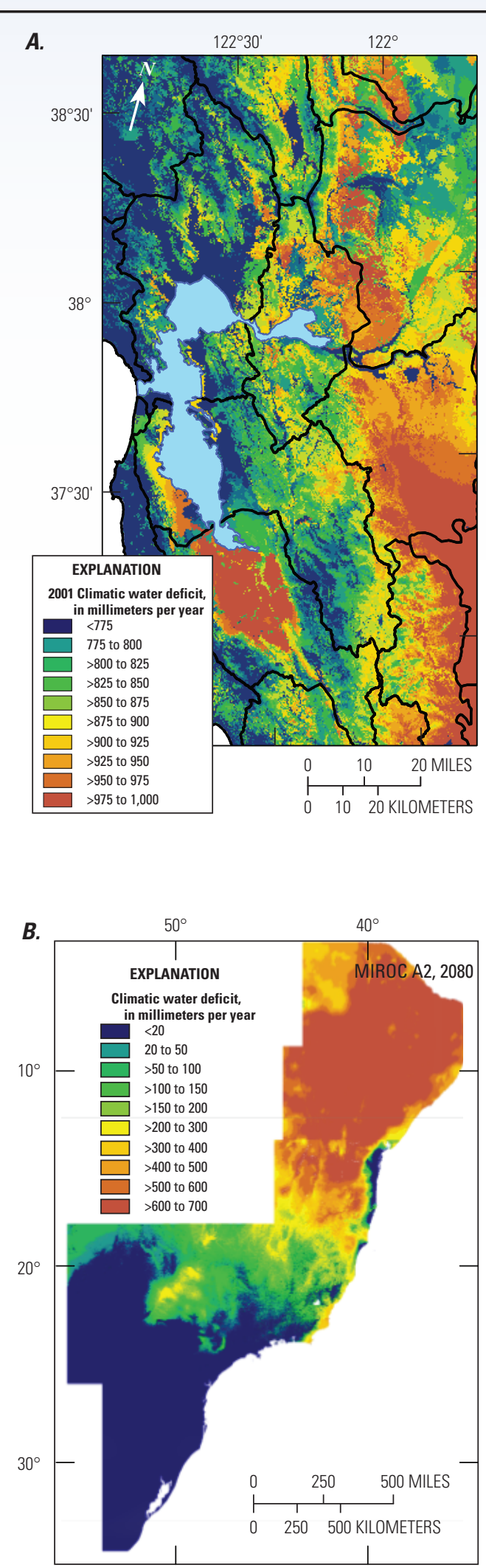

Figure 8. Climatic water deficit (CWD) for $A$, the San Francisco Bay area watersheds, where the CWD variation is clear as a result of coastal proximity, north and south facing hillslopes, and differing soil depths; and $B$, the Brazilian Atlantic Forest, which covers much of Brazil, where the CWD, as projected for 2080, varies from north to south. 
